\title{
Use of Multi-parameter Flow Cytometry as Tool to Monitor the Impact of Formic Acid on Saccharomyces carlsbergensis Batch Ethanol Fermentations
}

\author{
Cláudia Freitas - Elisabete Neves - Alberto Reis • \\ Paula C. Passarinho - Teresa Lopes da Silva
}

Received: 3 October 2012 / Accepted: 26 December $2012 /$

Published online: 29 January 2013

(C) Springer Science+Business Media New York 2013

\begin{abstract}
The use of lignocellulosic materials as substrate for bioethanol production is considered a cost-effective approach to make the biofuel production process economically sustainable. However, lignocellulosic hydrolysis releases toxic compounds such as weak acids which inhibit microorganism growth and ethanol production. In order to understand the physiological response of Saccharomyces carlsbergensis when fermenting glucose in the presence of formic acid (HF), the yeast growth was monitored by multi-parameter flow cytometry. Cytoplasmic membrane potential decreased as the HF concentration increased and as the yeast culture reached the stationary phase. However, the proportion of cells with permeabilized membrane did not increase with the HF concentration increase. The accumulation of reactive oxygen species was also monitored. Control and fermentations at low HF concentrations $(<1 \mathrm{~g} / \mathrm{L})$ resulted in a high proportion of highly oxidized cells at the stationary phase. The multi-parameter flow cytometry approach proved to be a useful tool to monitor the physiological stress response of $S$. carlsbergensis growth and ethanol production in the presence of HF, an inhibitor present in lignocellulosic hydrolysates. The information here obtained at near real time can be used to enhance second-generation bioethanol production process efficiency.
\end{abstract}

Keywords Lignocellulosic materials - Bioethanol - Saccharomyces carlsbergensis · Formic acid . Flow cytometry

\section{Introduction}

According to many analysts, at the present staggering rate of consumption, the world fossil oil reserves will be exhausted in less than 50 years. Therefore, it is urgent to find substitutes that match the current world energy demand [1].

C. Freitas - E. Neves - A. Reis - P. C. Passarinho - T. L. da Silva ( $\square)$

Laboratório Nacional de Energia e Geologia, Unidade de Bioenergia, Estrada do Paço do Lumiar, 22,

1649-038 Lisbon, Portugal

e-mail: teresa.lopesilva@lneg.pt 